\title{
POLA PEMANFAATAN SUMBER DAYA UDANG DOGOL (Metapenaeus ensis de Haan) SECARA BERKELANJUTAN DI PERAIRAN CILACAP DAN SEKITARNYA
}

\author{
Ali Suman"), Daniel R. Monintja"), John Haluan"), dan Mennofatria Boer"
}

\begin{abstract}
ABSTRAK
Penelitian ini bertujuan untuk menyusun strategi pemanfaatan sumber daya udang dogol (Metapenaeus ensis de Haan) secara berkelanjutan di perairan Cilacap dan sekitarnya. Penelitian dilaksanakan di perairan Cilacap dan sekitarnya dari bulan Mei 2001 sampai dengan bulan Juni 2003. Metode yang digunakan dalam penelitian ini adalah skoring, untuk menentukan jenis alat tangkap yang layak bagi pemanfaatan udang dogol secara berkelanjutan, holistik (swept area method dan surplus produksi) dan analitik untuk evaluasi stok udang dogol serta optimasi linear untuk kombinasi unit penangkapan yang optimal. Hasil penelitian menunjukkan bahwa berdasarkan pada aspek biologi, aspek teknis, aspek sosial dan aspek ekonomi, dana alat tangkap yang layak dan ideal untuk dikembangkan menurut prioritasnya adalah tramımel net pasif, trammel net aktif trip harian, trammel net aktif trip mingguan, dan jaring dogol. Udang dogol memijah sepanjang tahun dengan puncak pada bulan September dan rata-rata ukuran pertama kali matang kelamin adalah saat panjang karapas mencapai $31,80 \mathrm{~mm}$ serta udang dogol memiliki laju pertumbuhan dan laju kematian yang tinggi. Potensi lestari udang dogol di perairan Cilacap dan sekitarnya adalah 540 ton per tahun dengan upaya optimum 305 unit alat tangkap baku (trammel net aktif trip mingguan). Kombinasi unit penangkapan yang optimal diperoleh dengan mengoperasikan 3.813 unit alat tangkap tramme/ net pasif. Pola pemanfaatan sumber daya udang dogol secara berkelanjutan di perairan Cilacap dan sekitarnya dapat diwujudkan melalui 1) penutupan musim penangkapan selama sebulan setiap tahurnnya yaitu pada bulan September; 2) membatasi upaya penangkapan menjadi 3.813 unit alat tangkap trammel net pasif dengan keuntungan yang diperoleh Rp.47,90 milyar per tahun; dan 3) menerapkan sistem kuota melaui alokasi produksi 416 ton per tahun untuk Kabupaten Cilacap, 113 ton per tahun untuk Kabupaten Ciamis, dan 11 ton per tahun untuk Kabupaten Kebumen, sedangkan alokasi upaya penangkapan adalah 2.936 unit tram,mel net pasif bagi Kabupaten Cilacap, 801 unit untuk Kabupaten Ciamis, dan 76 unit untuk Kabupaten Kebumen.
\end{abstract}

KATA KUNCI: $\quad$ kelestarian, eksploitasi, Metapenaeus ensis, Cilacap

ABSTRACT: Sustainable exploitation pattern for the endeavour shrimp resources (Mietapenaeus ensis de Haan) in Cilacap and adjacent waters. By: Ali Suman, Daniel R. Monintja, John Haluan, and Mennofatria Boer

The objective of this research is to determine a strategy for sustainable exploitation pattern for the endeavour shrimp resources (M. ensis de Haan) in Cilacap and its adjacent waters. This research was conducted from May 2001 to June 2003. The evaluation was based on four models 1) scoring method to determine a kind of appropriate fishing unit for sustainable exploitation of this resources; 2) holistic and analytic method for the evaluation of stock; and 3) optimization model of linear program for the determination of optimal combination fishing units. The results show that the appropriaie fishing unit to be developed related to biological, social, technical, and economical aspects were the passive trammel net, active trammel net in daily trip, active trammel net in weekly trip, and dogol net in subsequently in priority. The size at first maturity of endeavour shrimp (M. ensis) was $31.80 \mathrm{~mm}$ in carapace length and spawned throughout the year with a peak in September and the growth and mortality rate higher. Maximum sustainable yield of endeavour sinrimp in Cilacap and adjacent waters is 540 ton per year and effort optimum is about 305 unit of fishing gear standard (active trammel net in weekly trip). The sustainable exploitation pattern of endeavour shrimp in Cilacap and adjacent waters should include 1) closed season during one month of September in one year; 2) restriction on effort to be 3,813 units of passive trammel net with a profit of Rp. 47.90 billion per year, arid 3) application of quota system with production allocation about 416 ton per year for Cilacap district, 113 per year for Ciamis district, and 11 ton per year for Kebumen district, while effort allocation is 2,936 units of passive trammel net for Cilacap district, 801 units of passive trammel net for Ciamis district, and 76 units of passive trammel net for Kebumen district.

KEYWORDS: $\quad$ sustainable, exploitation, Metapenaeus ensis, Cilacap

\section{PENDAHULUAN}

Udang dogol merupakan salah satu udang ekonomis penting di perairan Cilacap dan sekitarnya. Kontribusi produksi udang dogol di perairan ini mendominasi rata-rata sekitar $51 \%$ dari produksi udang penaeid dan secara nasional memberikan sumbangan produksi sekitar $5 \%$ setiap tahunnya (Naamin et al., 1992; Iskandiar et al., 1994). Pemanfaatan sumber daya udang di perairan ini

\footnotetext{
Peneliti pada Balai Riset Perikanan Laut, Jakarta

*) Fakultas Perikanan dan IImu Kelautan Institut Pertanian Bogor, Bogor
} 
sudah lama dilakukan, tetapi secara komersial baru dimulai pada tahun 1966, dengan mulai berkembangnya perikanan trawl untuk menangkap udang di perairan ini (Naamin, 1972; Gunadi, 1981). Sejak saat itu, perkembangan pemanfaatan udang di perairan ini sangat intensif dan meningkat setiap tahun akibat bertambahnya armada penangkapan dan angkatan kerja (Van Zalinge \& Naamin, 1975; Naamin, 1978).

Walaupun sumber daya udang termasuk sumber daya yang dapat pulih (renewable resources) tetapi penangkapan yang terus meningkat tanpa adanya pembatasan akan menyebabkan habisnya sumber daya tersebut. Mengingat tingginya intensitas penangkapan udang dogol di perairan Cilacap dan sekitarnya, yang dilakukan setiap hari sepanjang tahun, maka dikhawatirkan kondisi pemanfaatannya akan mengancam kelestarian dan keberlanjutan pemanfaatan sumber daya udang dogol di perairan ini. Hal ini, telah terindikasi dengan terjadinya penurunan produksi sekitar $46 \%$ dalam 13 tahun terakhir, padahal di lain pihak terjadinya kenaikan jumlah upaya penangkapan sekitar 30 sampai dengan $40 \%$. Dalam kaitan ini, Naamin (1984) mengatakan bahwa penambahan jumlah upaya penangkapan pada batas tertentu akan menyebabkan peningkatan produksi, tetapi apabila terus terjadi penambahan upaya, maka pada suatu saat akan terjadi penurunan stok. Dengan demikian, apabila kondisi pola pemanfaatan yang ada saat ini tetap berjalan, maka diduga dalam jangka panjang akan dapat menyebabkan sumber daya udang dogol di perairan Cilacap dan sekitarnya terancam mengalami kepunahan. Melihat fenomena yang ada tersebut, maka di perairan Cilacap dan sekitarnya harus dilakukan upaya-upaya pengelolaan pemanfaatan sumber daya udang dogol yang lebih baik, sehingga sumber daya udang dogol yang ada dapat menjad modal bagi perbaikan (recovery) stok dalam kaitan pemanfaatannya secara berkelanjutan. Agar pemanfaatan sumber daya udang dogol di perairan Cilacap dan sekitarnya dapat dilakukan secara berkelanjutan, maka pengelolaannya harus didasarkan pada pengetahuan tentang keadaan stok dan aspek biologi serta aspek sosial ekonomi dan teknologi penangkapannya. Dengan demikian, potensi lestari dan optimalisasi pemanfaatan sumber daya udang dogol dapat ditentukan serta selanjutnya dapat disusun suatu strategi pemanfaatan sumber daya udang dogol yang berkelanjutan di perairan Cilacap.

\section{BAHAN DAN METODE}

Penelitian ini dilakukan dari bulan Mei 2001 sampai dengan Juni 2003 di perairan Cilacap dan sekitarnya (Gambar 1). Penelitian dilakukan dengan pengamatan langsung di pusat-pusat pendaratan udang di perairan Cilacap dan sekitarnya (PPSC, tempat penangkapan ikan Sidakaya, tempat penangkapan ikan Argopeni, dan tempat penangkapan ikan Pangandaran). Seluruh pengumpulan data untuk keperluan pengkajian stok dan sosial ekonomi dilakukaan dengan metode survei. Analisis data untuk determinasi alat tangkap digunakan metode skoring (Monintja, 1987; Haluan \& Nurani, 1988; Mangkusubroto \& Trisnadi, 1985),

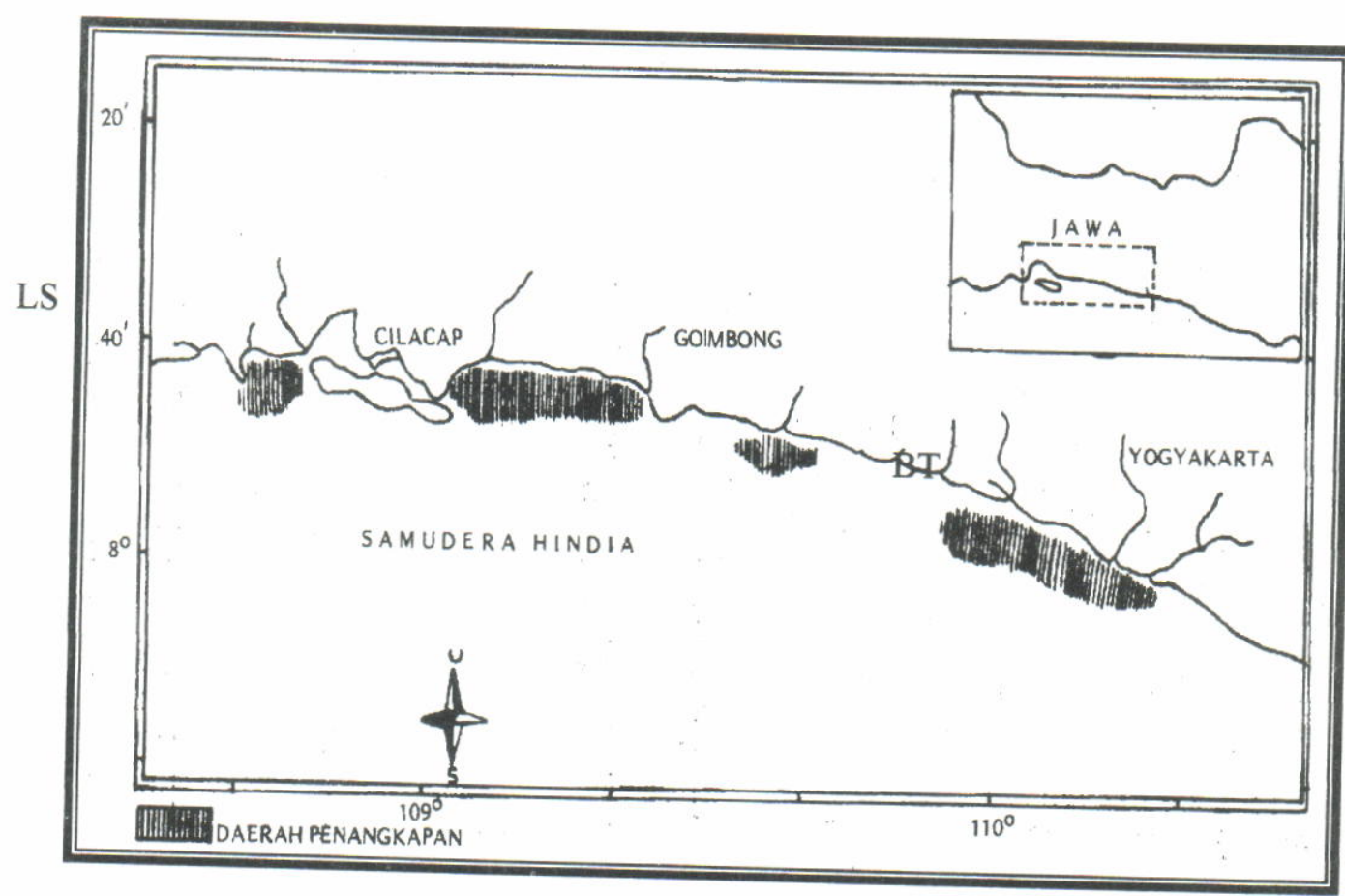

Gambar 1.

Figure 1. Daerah penangkapan udang dogol di perairan Cilacap dan sekitarnya
Fishing grown of endeavour shrimp in Cilacap and adjacent waters. 
sedangkan untuk analisis kajian stok digunakan 2 metode yaitu 1) metode analitik untuk menganalisis rata-rata ukuran matang kelamin, musim pemijahan, parameter pertumbuhan, dan laju kematian (Udupa, 1986; Martosubroto, 1978; Gayanilo et al., 1993; Sparre \& Venema, 1992; Pauly, 1980) dan 2) model holistik untuk menduga potensi lestari (Sparre \& Venema, 1992). Sementara itu, untuk analisis optimasi digunakan model program linier (Soekartawi, 1995).

\section{HASIL DAN BAHASAN}

\section{Determinasi Unit Penangkapan Udang Dogol}

Tujuan determinasi unit penangkapan udang adalah untuk mendapatkan jenis alat tangkap udang dogol yang mempunyai keragaan (performance) yang baik ditinjau dari aspek biologi, teknis, ekonomi, dan sosial sehingga merupakan alat tangkap yang cocok untuk dikembangkan bagi pemanfaatan sumber daya udang dogol secara berkelanjutan (Monintja, 1987; Haluan \& Nurani, 1988)

Di perairan Cilacap dan sekitarnya hanya terdapat 2 jenis alat tangkap udang dogol yang utama tetapi dalam pengoperasiannnya dapat dikategorikan menjadi 4 macam yaitu trammel net aktif trip harian, trammel net aktif tip mingguan, trammel net pasif, dan jaring jogol. Konsekuensi logisnya, maka hal ini akan menimbulkan perbedaan dalam aspek biologi, teknis, sosial, dan ekonomi. Oleh karena itu, dalam analisis berdasarkan pada aspek biologi teknis, sosial, dan ekonomi dilakukan terhadap 4 kategori alat tangkap. Pada Tabel 1 disajikan hasil skoring yang dilakukan terhadap 4 kategori alat tangkap udang dogol yang ada di perairan Cilacap dan sekitarnya berdasarkan pada analisis aspek biologi, teknis, sosial, dan ekonomi.

Berdasarkan pada Tabel 1 selanjutnya dilakukan standarisasi dengan menggunakan fungsi nilai pada penilaian aspek biologi, teknis, sosiai, dan ekonomi (Mangkusubroto \& Trisnadi, 1985) dan didapatkan hasil seperti disajikan pada Tabel 2 .

Hasil standarisasi yang dilakukan terhadap 4 kategori alat tangkap udang dogol (Tabel 2) dapat terseleksi alat tangkap yang layak untuk dikembangkan dalam rangka pemanfaatan sumber daya udang dogol secara berkelanjutan di perairan Cilacap dan sekitarnya. Alat tangkap trammel net aktif trip mingguan terlihat menempati prioritas pertama sebagai alat tangkap yang layak dikembangkan, trammel net pasif pada urutan ke-2, trammel net aktif trip harian urutan ke-3, dan jaring dogol sebagai pilihan terakhir (ke-4) untuk dikembangkan. Urutan prioritas ini dapat digunakan sebagai bahan pertimbangan dalam menentukan pengembangan alat tangkap di perairan Cilacap dan sekitarnya, namun sebagai dasarnya harus tetap ditunjang informasi tentang potensi sumber daya udang dogol serta upaya optimum yang diizinkan.

Tabel 1. Hasil analisis penilaian aspek biologi, teknis, sosial, dan ekonomi unit penangkapan udang dogol di perairan Cilacap dan sekitarnya

Table 1. Result of value analysis on economic, social, technique, and biologycal aspect of fishing unit of endeavour shrimp in Cilacap and adjacent waters

\begin{tabular}{ccccccccc}
\hline Alat & \multicolumn{7}{c}{ Kriteria penilaian } \\
\cline { 2 - 9 } tangkap & $\mathbf{X 1}$ & UP & X2 & UP & X3 & UP & X4 & UP \\
\hline TNA & 3,00 & 1 & 4,00 & 1 & 1,19 & 3 & 1,00 & 3 \\
TNB & 1,07 & 2 & 0,87 & 2 & 1,85 & 2 & 1,54 & 2 \\
TNC & 0,29 & 3 & 0,09 & 3 & 3,00 & 1 & 1,78 & 1 \\
JD & 0,00 & 4 & 0,87 & 2 & 0,49 & 4 & 0,42 & 4 \\
\hline
\end{tabular}

Keterangan/Remark: TNA $=$ trammel net aktif trip mingguan; TNB $=$ trammel net aktif trip harian; TNC $=$ trammel net pasif; JD = jaring dogol; $\mathrm{X} 1=$ aspek biologi; $\mathrm{X} 2=$ aspek teknis; $\mathrm{X} 3=$ aspek sosial, $\mathrm{X} 4=$ aspek ekonomi; UP = urutan prioritas

Tabel 2

Standarisasi aspek biologi, teknis, sosial, dan ekonomi unit penangkapan udang dogol di perairan Cilacap dan sekitarnya

Table 2. Standarization of economic, social, technique, and biologycal aspect of endeavour shrimp catching unit in Cilacap and adjacent waters

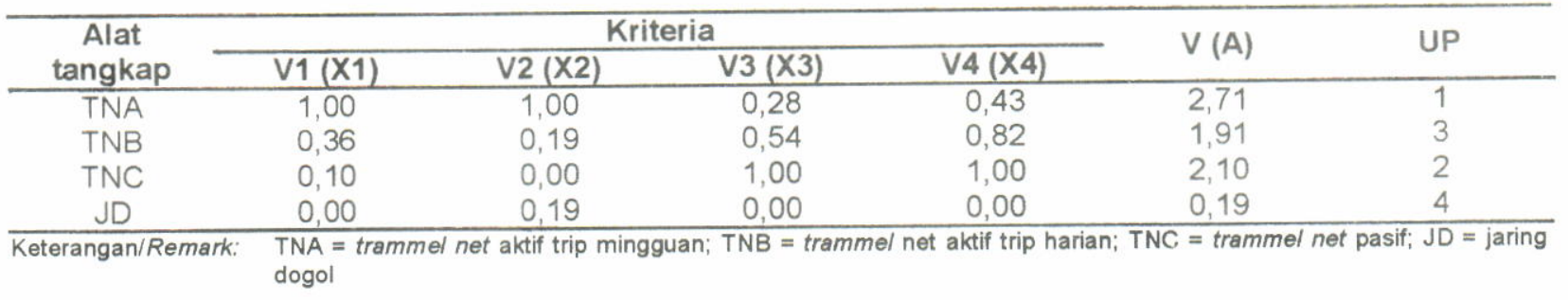


Tabel 3. Sebaran frekuensi (\%) udang dogol ( $M$. ensis) yang matang kelamin pada berbagai ukuran di perairan Cilacap dan sekitarnya

Table 3. Frequency distribution (\%) of endeavour shrimp (M. ensis) on many size and gonad maturity in Cilacap and adjacent waters

\begin{tabular}{cc}
\hline Panjang karapas $(\mathrm{mm})$ & Persentase (\%) \\
\hline 24 & 5 \\
26 & 6 \\
28 & 9 \\
30 & 16 \\
32 & 41 \\
34 & 57 \\
36 & 62 \\
38 & 70 \\
40 & 80 \\
42 & 100 \\
44 & 100 \\
46 & 100 \\
48 & 100 \\
50 & 100 \\
\hline
\end{tabular}

\section{Rata-Rata Ukuran Pertama Kali Matang dan Musim} Pemijahan

Ukuran udang pada saat kematangan penting artinya dalam pengelolaan perikanan mengingat bahwa eksploitasi harus membiarkan sejumlah tertentu induk-induk ikan (udang) yang mempunyai ukuran sama atau lebih dari ukuran tersebut pada saat mencapai kematangan (Sudjastani, 1974). Pada umumnya udang betina mengalami kematangan kelamin pada ukuran yang lebih besar daripada udang jantan (Martosubroto, 1978). Penyebaralı persentase banyaknya udang dogol yang matang kelamin pada berbagai ukuran disajikan pada Tabel 3.

Analisis lebih lanjut dari Tabel 2 dengan menggunakan metode Spearman-Karber (Udupa, 1986) didapatkan rata-rata udang dogol vertama kali matang kelamin pada panjang karapas $31,80 \mathrm{~mm}$.
Dibandingkan dengan udang dogol dari periode penelitian sebelumnya di perairan Cilacap, ternyata udang dogol di perairan Cilacap dan sekitarnya mengalarni lebih awal rata-rata kematangan gonadnya (panjang karapasnya $36,8 \mathrm{~mm}$ ), tetapi lebih lambat bila dibandingkan dengan keadaan di perairan Tanjung Krawang (panjang karapas $20 \mathrm{~mm}$ ) (Martosubroto, 1978; Suman, 1990).

Selanjutnya, untuk mengetahui musim pemijahan udang di suatu perairan diteliti melalui pengamatan terhadap penyebaran densitas telur atau dapat pula melalui pengamatan terhadap kematangan gonad udang betina di perairan tersebut (Martosubroto, 1978). Selama penelitian ini diperoleh udang betina yang belum matang gonad 888 ekor $(41 \%)$ dan yang matang kelamin 1.270 ekor (59\%). Pada Tabel 4 diterakan persentase udang dogol betina yang berada dalam tingkatan matang kelamin di perairan Cilacap dan sekitarnya.

Tabel 4. Sebaran frekuensi (\%) udang dogol ( $M$. ensis) berdasarkan pada tingkat kematangan gonad di perairan Cilacap dan sekitarnya

Table 4. Frequency distribution (\%) of endeavour shrimp depend on gonad maturity in Cilacap and adjacent waters

\begin{tabular}{llcc}
\hline \multirow{2}{*}{ Tahun } & \multicolumn{2}{c}{ Bulan } & \multicolumn{2}{c}{ Tingkat kematangan } \\
\cline { 3 - 4 } 2001 & Mei & Belum matang & Matang \\
& Juni & 41 & 59 \\
& Juli & 39 & 61 \\
& Agustus & 34 & 66 \\
& September & 45 & 86 \\
& Oktober & 14 & 47 \\
& Nopember & 53 & 38 \\
& Desember & 62 & 54 \\
\hline 2002 & Januari & 46 & 51 \\
& Pebruari & 49 & 62 \\
& Maret & 38 & 55 \\
\end{tabular}


Dari Tabel 4 tersebut terlihat bahwa udang dogol melakukan pemijahan sepanjang tahun dengan puncaknya pada bulan September. Dan kepentingan dari pengetahuan musim pemijahan dalam prinsip pemanfaatan sumber daya udang dogol serta berkelanjutan adalah untuk mengetahui kapan waktunya diadakan penutupan daerah dan musim penangkapan dalam rangka memberi kesempatan pada induk-induk udang untuk melakukan pemijahan.

\section{Parameter Pertumbuhan dan Laju Kematian}

Dengan merunut data frekuensi panjang karapas dari bulan ke bulan dengan program ELEFAN (Sparre \& Venema, 1992) diperoleh laju pertumbuhan (K) udang dogol jantan di perairan Cilacap dan sekitarnya 1,49 per tahun dan panjang karapas maksimum $\left(L_{\infty}\right)$ sebagai $41,5 \mathrm{~mm}$. Untuk udang dogol betina nilai laju pertumbuhannya (K) 1,52 per tahun dan panjang karapas maksimum (Lњ) 52,2 mm. Dengan demikian, persamaan pertumhuan von Bertalanffy untuk udang dogol di perairan Cilacap dan sekitarnya sebagai berikut:

$$
\begin{aligned}
& L t=41,4\left[1-e^{-1,49(t+0,003)}\right] \text { untuk udang jantan } \\
& L t=52,2\left[1-e^{-1,52(t+0,023)}\right] \text { untuk udang betina }
\end{aligned}
$$

Nilai $K$ udang dogol betina juga terlihat lebih besar dari nilai $\mathrm{K}$ udang jantan dan hal ini tercermin juga dalam hasil tangkapan, di mana ukuran udang dogol betina didapatkan selalu lebih besar dari udang jantan. Dall et al. (1990) mengatakan bahwa pertumbuhan udang betina selalu lebih cepat dari udang jantan dan pada umur yang sama selalu ditemui udang betina lebih besar dari udang jantan Nilai $\mathrm{K}$ udang dogol yang lebih besar dari 1 juga menunjukkan bahwa udang dogol ini mempunyai pertumbuhan yang cepat (Gulland, 1983; Naamin, 1984). Cepatnya pertumbuhan dan pendeknya umur udang dogol menunjukkan bahwa laju kematian cukup tinggi. Hal ini, memberikan peringatan kepada kita agar memperhatikan pemanfaatannya secara berkelanjutan. Sehubungan dengan umur, laju pertumbuhan dan kematian ini yang perlu diperhatikan adalah kapan waktu yang tepat untuk menangkapnya, baik ditinjau dari sumber dayanya sendiri maupun dari segi ekonominya. Kalau kita terlambat menangkapnya tentu udang ini akan mati percuma, sedangkan kalau terlalu cepat ditangkap secara ekonomi dan kelestarian sumber daya juga kurang menguntungkan.

Selanjutnya, dengan menggunakan parameter pertumbuhan udang dogol yang telah dihitung ( $K=1,52$ per tahun, $L_{-\infty}=52,2 \mathrm{~mm}$ untuk udang betina serta $K=1,49$ per tahun dan $L_{\infty}=41,5 \mathrm{~mm}$ untuk udang jantan) sebagai bahan masukan untuk membuat kurva hasil tangkap, diperoleh nilai dugaan $Z$ untuk udang dogol betina sebagai 6,52 per tahun dan 8,68 per tahun untuk udang jantan (Gambar 2). Nilai dugaan laju kematian alamiah (M) dihitung dengan menggunakan persamaan Pauly (1980) dan diperoleh niali $M$ untuk udang dogol betina 2,01 per tahun dan untuk udang jantan 2,12 per tahun. Nilai dugaan laju kematian karena penangkapan (F) dihitung dan diperoleh hasil 4,51 per tahun untuk udang dogol betina serta 6,56 per tahun untuk udang dogol jantan.

\section{Potensi Lestari dan Upaya Optimum Udang Dogol}

Potensi lestari (maximum sustainable yield) yang merupakan suatu produksi perikanan yang dapat dipertahankan secara berlanjut, adalah suatu parameter pengelolaan yang dihasilkan dalam pengkajian stok sumber daya perikanan dan merupakan suatu unsur penunjang bagi peluang pengembangan di suatu wilayah (Karyana \& Badrudin, 1992). Dengan asumsi bahwa unit upaya baku bagi penangkapan udang dogol adalah trammel net aktif trip mingguan, maka pada Tabel 5 disajikan data total upaya dan catch per unit of effort secara berseri dalam kurun waktu 13 tahun terakhir
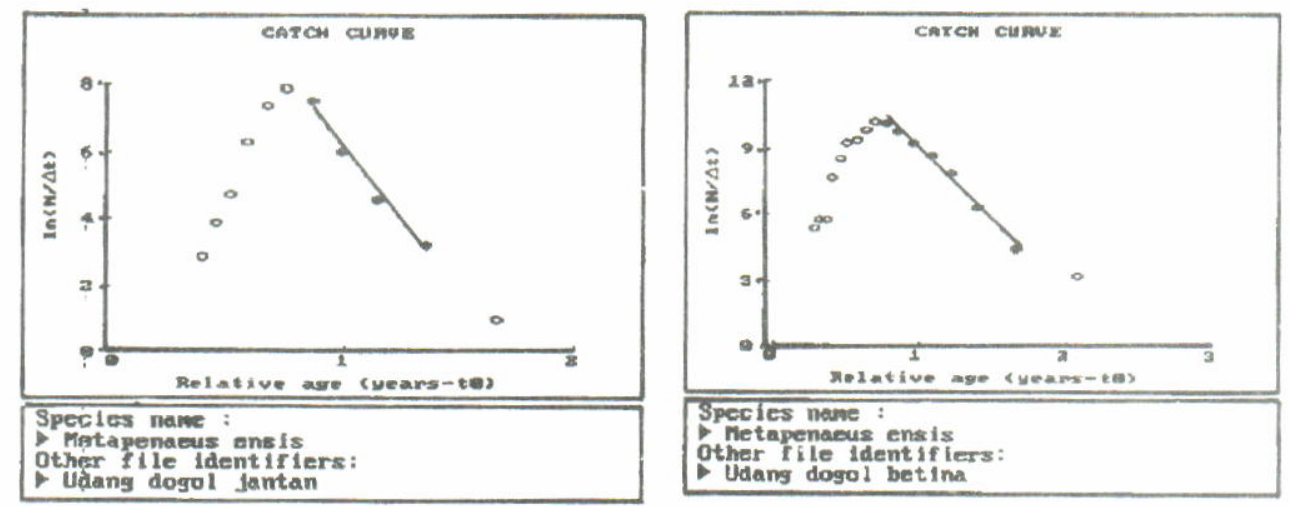

Gambar 2. Nilai Z sebagai slope hasil tangkapan udang dogol ( $M$. ensis de Haan) di perairan Cilacap dan sekitarnya.

Figure 2. The value of $z$ as slope of endeavour shrimp (M. ensis de Haan) catch in Cilacap and adjacent waters. 
Tabel 5. Perkembangan produksi, upaya penangkapan, dan hasil per unit upaya (catch per unit of effort) udang dogol di perairan Cilacap dan sekitarnya

Table 5. Yield growth, effort, and catch per unit effort of endeavour shrimp in Cilacap and adjacent waters

\begin{tabular}{cccc}
\hline Tahun & Produksi (ton) & Upaya (unit) & CPUE (ton) \\
\hline 1990 & 578,9 & 385 & 1,5 \\
1991 & 569,4 & 256 & 2,2 \\
1992 & 344,6 & 383 & 0,9 \\
1993 & 560,3 & 206 & 2,7 \\
1994 & 414,7 & 503 & 0,8 \\
1995 & 415 & 611 & 0,8 \\
1996 & 348,7 & 489 & 0,7 \\
1997 & 464 & 233 & 2,0 \\
1998 & 461,2 & 269 & 1,7 \\
1999 & 665,5 & 368 & 1,8 \\
2000 & 487,8 & 409 & 1,2 \\
2001 & 321,1 & 432 & 0,7 \\
2002 & 313,5 & 418 & 0,8 \\
\hline
\end{tabular}

Dari perhitungan data dari Tabel 5 dengan model linier Schaefer (Sparre \& Venema, 1992) diperoleh potensi lestari (maximum sustainable yield) udang dogol di perairan Cilacap dan sekitarnya 540 ton dan upaya optimum ( $f_{\text {opt }}$ ) sekitar 305 unit unit trammel net serta $r^{2}=0,83$. Kondisi pemanfaatan saat ini memperlihatkan upaya yang ada telah melampaui upaya optimum.

\section{Optimasi Pemanfaatan Sumber Daya Udang Dogol}

Berdasarkan pada data yang ditemukan di lapangan, fungsi-fungsi yang digunakan dalam penelitian ini sebagai beriku:

1. Fungsi tujuan, yaitu memaksimumkan keuntungan usaha pemafaatan sumber daya udang dogol:

$$
\pi=19.120 .000 \quad \times 1=15.598 .000 \quad \times 2+12.570 .000
$$$$
\mathrm{X} 3+10.482 .00 \times 4
$$

di mana:

$\pi=$ keuntungan yang akan dimaksimumkan

X1 = jumlah armada trammel net aktif trip mingguan

X2 = jumlah armada tramme/ net aktif trip harian

$\mathrm{X} 3=$ jumlah armada trammel net passif

X4 = jumlah armada jarring dogol

2. Fungsi pembatas, yaitu nilai-nilai yang tidak boleh dilampaui, kalau terlampaui, maka akan merusak kelestarian sumber daya. Fungsi pembatas tersebut sebagai berikut:

a. Hasil tangkapan yang lestari (CMSY)

Suatu jenis udang di daerah tropis seperti di Indonesia dapat ditangkap oleh lebih dari 1 jenis alat tangkap, sehingga hasil tangkapan gabungan dari beberapa jenis alat tangkap terhadap udang dogol harus $\leq$ CMSY. Fungsi pembatas udang dogol terhadap hasii tangkapan lestari sebagai berikut:

\section{$1,2 \times 1+0,3 \times 2+0,1 \times 3+0,3 \times 4 \leq 540$}

b. Upaya penangkapan yang lestari (EMSY)

Berdasarkan pada data, maka fungsi pembatas terhadap upaya penangkapan sebagai berikut:

$X 1+0,25 \times 2+0,08 \times 3+0,25 \times 4 \leq 305$

3. Output, yaitu berdasarkan pada hasil analisis optimasi dengan linear programming terhadap fungsi tujuan dan pembatas yang telah ditentukan sebelumnya, diperoleh hasil untuk tidak mengoperasikan alat tangkap trammel net aktif trip mingguan, trammel net aktif trip harian, dan jaring dogol dalam pemanfaatan sumber daya udang dogol secara berkelanjutan. Nilai optimal jenis alat tangkap yang direkomendasikan yaitu 3.813 unit trammel net pasif dengan keuntungan Rp.47,9 milyar.

\section{Pola Pemanfaatan Sumber Daya Udang Dogol secara Berkelanjutan}

Dari 2 garis besar metode pengelolaan pemanfaatan sumber daya udang yaitu pengontrolan ukuran udang yang tertangkap dan pengontrolan jumlah penangkapan (Gulland, 1972), maka yang dapat diaplikasikan dalam pemanfaatan sumber daya udang dogol secara berkelanjutan di perairan Cilacap dan sekitarnya adalah pengontrolan jumlah penangkapan. Pembatasan atau penentuan ukuran udang terkecil yang boleh didaratkan dan ukuran mata jaring yang terkecil tidak dapat dilaksanakan, karena di perairan Cilacap dan sekitarnya yuwana dari udang dogol yang harus dilindungi dan udang dewasa dari jenis-jenis udang kecil lainnya terdapat pada daerah yang sama (bercampur). Kesukaran lain 
ialah jika sebagian hasil tangkap nelayan terdiri atas udang-udang dengan ukuran di bawah ukuran udang terkecil yang telah ditetapkan, akan membuat nelayan membuang kembali hasil tangkapannya ke laut dan akan terbuang percuma karena akan mati sendiri. Sedangkan pengaturan ukuran mata jaring juga tidak dapat diterapkan karena menurut Gulland (1972) metode ini kurang efektif untuk udang penaeid (udang dogol) karena proses seleksi tidak begitu efisien. Hal ini, mengingat udang penaeid (udang dogol) memiliki rostrum dan appendages (pencuatan-pencuatan) yang akan menghambat lolosnya udang dari mata jaring.

Dengan demikian, metode pengelolaan yang layak dilaksanakan dalam pemanfaatan sumber daya udang dogol secara berkelanjutan di perairan Cilacap dan sekitarnya adalah seperti tersaji pada Tabel 6 .

Dari penerapan metode pengelolaan pemanfaatan berupa pembatasan upaya penangkapan udang dogol didapatkan 2 alternatif pola pemanfaatan sumber daya udang dogol yang berkelanjutan di perairan Cilacap dan sekitarnya (Tabel 6). Alternatif pertama dengan model Schaefer adalah dengan mengurangi jumlah upaya sekitar 113 unit dari yang ada saat ini. Berdasarkan pada kriteria analisis optimasi dengan program linier, maka yang harus dikurangi adalah 64 unit alat tangkap trammel net aktif trip mingguan dan
195 unit alat tangkap jaring dogol. Alternatif pertama ini tidak mendapat keuntungan yang maksimum bagi nelayan yaitu hanya Rp. 21,10 milyar per tahun, yang berarti lebih rendah dari alternatif ke- 2 .

Alternatif yang ke-2 adalah hasil optimasi dengan linear programing yaitu rekomendasi untuk menghapus alat tangkap trammel net aktif trip mingguan, trammel net aktif trip harian, dan jaring dogol untuk menangkap udang dogol di perairan Cilacap dan sekitarnya. Dengan demikian, alat tangkap yang disarankan dalam pemanfaatan sumber daya udang dogol secara berkelanjutan adalah 3.813 unit alat tangkap trammel net pasif. Dalam jangka panjang skenario yang ke-2 inilah yang paling layak, karena dapat memanfaatkan sumber daya secara optimum dan lestari dengan keuntungan yang tınggi yaitu Rp.47,9 milyar per tahun. Untuk alat tangkap yang direkomendasikan dihilangkan yaitu 188 unit alat tangkap trammel net aktif trip mingguan disarankan untuk mengalokasikannya menjadi alat tangkap pelagis besar sesuai dengan izin peruntukannya, sementara untuk 407 unit alat tangkap trammel net aktif trip harian dan 195 unit alat tangkap jaring dogol dapat dialokasikan seluruhnya menjadi 1.806 unit alat tangkap trammel net trip pasif. Kekurangan 1.025 unit trammel net pasif untuk pengusahaan sumber daya udang dogol secara optimal dan lestari dapat merupakan peluang investasi di perairan Cilacap dan sekitarnya.

Tabel 6. Pola pemanfaatan sumber daya udang dogol di perairan Cilacap dan sekitarnya

Table 6. The pattern for the endeavour shrimp resources in Cilacap and adjacent waters

\begin{tabular}{|c|c|c|}
\hline Komponen & Strategi & Proses \\
\hline 1. Upaya penangkapan & $\begin{array}{l}\text { Pembatasan alat tangkap } \\
\text { menjadi } 124 \text { unit alat tangkap } \\
\text { trammel net aktif trip mingguan, } \\
407 \text { unit alat tangkap trammel } \\
\text { net aktif trip harian, dan } 982 \\
\text { unit alat tangkap trammel net } \\
\text { pasif. }\end{array}$ & $\begin{array}{l}\text { - Pengurangan } 195 \text { unit alat } \\
\text { tangkap jaring dogol dan } 64 \\
\text { unit alat tangkap trammel net } \\
\text { aktif trip mingguan. }\end{array}$ \\
\hline & $\begin{array}{l}\text { Pembatasan upaya menjadi } \\
3.813 \text { unit alat tangkap trammel } \\
\text { net pasif. }\end{array}$ & $\begin{array}{l}\text { - } 407 \text { unit alat tangkap trammel } \\
\text { net aktif trip harian dan } 195 \\
\text { unit jaring dogol diubah } \\
\text { menjadi } 1.806 \text { unit trammel } \\
\text { net pasif dan kekurangannya } \\
1.025 \text { unit merupakan } \\
\text { peluang investasi. }\end{array}$ \\
\hline
\end{tabular}

2. Penutupan musim penangkapan - Penutupan dilakukan 1 bulan dalam setahun yaitu pada bulan September yang dibatasi pada kedalaman $40 \mathrm{~m}$ ke atas.

3. Kuota
- Alokasi produksi 416 ton per th bagi Cilacap, 113 ton per th bagi Ciamis dan 11 ton per th bagi Kebumen, sedang alokasi upaya berupa 2.936 unit bagi Cilacap, 801 unit bagi Ciamis, dan 76 unit bagi Kebumen.
- Penutupan dilakukan pada seluruh daerah penangkapan udang.

- pengaturan alokasi dikordinasikan oleh ke-3 pemerintah kabupaten. 
Konsekuensi logis dari penerapan alternatif ke-2 pola pemanfaatan sumber daya udang dogol di perairan Cilacap dan sekitarnya akan berdampak kepada terpenuhinya kriteria pemanfaatan yang berkelanjutan serta dapat meningkatkan kesejahteraan nelayan seperti disajikan pada Tabel 7.

Selanjutnya, pengelolaan pemanfaatan sumber daya udang dogol yang dapat diaplikasikan di perairan Cilacap dan sekitarnya adalah kuota penangkapan. Kuota penangkapan yang dilakukan adalah dengan membagi potensi lestari udang dogol yang ada berdasarkan pada kemampuan wilayah kabupaten di perairan Cilacap dan sekitarnya dalam menangkap udang dogol ini. Prinsip kuota ini sangat sejalan juga dengan prinsip otonomi daerah yang mulai berlaku sejak tahun 1999. Berdasarkan pada kemampuan penangkapan udang per wilayah tersebut, maka alokasi penangkapan 416 ton per tahun untuk Kabupaten Cilacap, 113 ton per tahun untuk Kabupaten Ciamis, dan 11 ton per tahun untuk Kabupaten Kebumen. Untuk mengusahakan alokasi produksi ini, maka dialokasikan jumlah upaya penangkapan di Kabupaten Cilacap 2.936 unit alat tangkap trammel net pasif, di Kabupaten Ciamis 801 unit dan di Kabupaten Kebumen 76 unit. Dalam hal ini terlihat dominasi penangkapan terpusat di Kabupaten Cilacap dan hal ini adalah wajar mengingat nelayan Cilacap adalah nelayan yang trampil dan paling unggul dalam menangkap udang di perairan Cilacap dan sekitarnya. Di samping itu, daerah Cilacap merupakan daerah yang paling besar sumbangannya dalam produksi udang karena merupakan pusat daerah asuhan udang di perairan Cilacap darı sekitarnya (Naamin, 1972; Van Zalinge \& Naamin, 1975; Martosubroto \& Naamin, 1977).

Dari pola pemanfaatan sumber daya udang dogol yang akan diterapkan di perairan Cilacap dan sekitarnya seperti yang tersaji pada Tabel 6 dan 7 terlihat menjamin pemanfaatannya secara berkelanjutan yang sesuai dengan kriteria yang dikemukakan Monintja (2000) sebagai berikut:

1. Hasil tangkapan tidak melebihi jumlah yang boleh dimanfaatkan, yang terealisasi dari tingkat produksi yang tidak boleh melebihi potensi lestari 540 ton per tahun.

2. Menggunakan bahan bakar lebih sedikit, di mana hal ini tercermin dari penghematan bahan bakar sekitar 56\% (15 I) per unit per hari. Pada kondisi sekarang rata-rata biaya bahan bakar adalah sekitar Rp.60.000,- dan setelah kebijakan diproyeksikan hanya memerlukan biaya sekitar Rp.30.000.-

3. Secara hukum, alat tangkap legal, di mana seluruh unit armada yang diproyeksikan adalah sesuai untuk beroperasi di jalur penangkapan I. yang merupakan daerah penangkapan udang. Pada saat ini sekitar 188 unit armada penangkapan udang dogol yaitu alat tangkap trammel net aktif trip mingguan adalah illegal karena izinnya di jalur III, tetapi pada kenyataannya beroperasi di jalur I karena komoditas yang menjadi tujuan penangkapannya berada di jalur I. Dalam alternatif pola pemanfaatan yang diusulkan armada ini dihapuskan dan sebagai alternatif untuk armada ini diubah menjadi armada penangkapan ikan pelagis di jalur III.

4. Investasi yang dibutuhkan rendah, yang tergambar dari turunnya biaya investasi sekitar $46 \%$ (Rp. 14 juta) dari kondisi yang ada sekarang. Proyeksi dalam strategi ini setiap unit armada membutuhkan biaya investasi Rp.16,7 juta, di mana biaya investasi sebelumnya mencapai biaya Rp.30,7 juta per unit armada penangkapan udang dogol

5. Produk mempunyai pasar yang baik, terutama untuk tujuan ekspor. Dengan pola ini, maka proses produksi telah memperhatikan kaidahkaidah keberlajutan dan berwawasan lingkungan, dan dengan demikian akan menjamin pasar produk ini di luar negeri.

Hal yang sama juga dikatakan Dahuri (2002) bahwa perikanan yang berkelanjutan harus berdimensi 3 hal yaitu aspek ekologi (environmentally friendly), ekonomi (economically sound), dan sosial (social just). Dari penerapan strategi pemanfaatan sumber daya udang dogol di perairan Cilacap dan

Tabel 7.

Konsekuensi logis penerapan pola pemanfaatan sumber daya udang dogol secara berkelanjutan di perairan Cilacap dan sekitarnya

Table 7. The application logic of sustainable exploitation pattern of endeavour shrimp resources in Cilacap and adjacent waters

\begin{tabular}{cll}
\hline No. & \multicolumn{1}{c}{ Komponen } & \multicolumn{1}{c}{ Dampak } \\
\hline 1. & Biaya investasi & lebih rendah sekitar 46\% (Rp. 14 juta) \\
2. & Bahan bakar & lebih hemat $56 \%$ (15 It) per trip \\
3. & Penangkapan ilegal & pencegahan 188 unit armada \\
4. & Kelestarian sumber & pengusahaan pada tingkat potensi lestari \\
5. & Pendapatan nelayan & naik sekitar $97 \%$ (Rp. 23,6 milyar) \\
6. & Pendapatan asli daerah & naik sekitar 100\% (Rp. 1,2 milyar) \\
7. & Penyerapan tenaga kerja & meningkat sekitar 44\% (2.328 orang) \\
8. & Kesempatan berusaha & meningkat sekitar $115 \%$ (2.041 orang) \\
9. & Pasar & lebih terjamin \\
\hline
\end{tabular}


sekitarnya terlihat ke-3 hal ini dapat terintegrasi dengan baik.

Agar pengelolaan perranfaatan sumber daya udang dogol di perairan Cilacap dan sekitarnya dapat terlaksana dengan efisien dan efektif, maka ke-3 cara pengelolaan tersebut harus dilaksanakan secara bersamaan. Kombinasi yang ideal dalam cara pengelolaan ini yaitu penutupan musim penangkapan pada bulan September setiap tahun pada kedalaman $40 \mathrm{~m}$ atau lebih, pembatasan upaya penangkapan sesuai dengan skenario penangkapan yang ke-2 dan kuota penangkapan, juga harus dibarengi dengan pemantauan dan penegakan hukum serta koordinasi 3 pemerintah kabupaten.

\section{KESIMPULAN DAN SARAN}

\section{Kesimpulan}

1 Pola pemanfaatan sumber daya udang dogol secara berkelanjutan di perairan Cilacap dan sekitarnya diusulkan 3 alternatif pola pemanfaatan yaitu penutupan musim penangkapan, pembatasan upaya penangkapan dan penetapan kuota penangkapan. Penutupan musim penangkapan udang dogol di perairan Cilacap dan sekitarnya ciliakukan setiap bulan September setiap tahunnya, sedangkan pembatasan upaya penangkapan udang dogol sekitar 3.813 unit alat tangkap trammel net pasif setiap tahunnya. Sementara itu, penetapan kuota penangkapan 416 ton untuk Kabupaten Cilacap, 113 ton untuk Kabupaten Ciamis, dan 11 ton untuk Kabupaten Kebumen serta alokasi jumlah upaya penangkapan 2.936 unit trammel net pasif untuk Kabupaten Cilacap, 801 unit untuk Kabupaten Ciamis, dan 76 unit untuk Kabupaten Kebumen.

2 Penerapan pola pemanfaatan sumber daya udang dogol secara berkelanjutan di perairan Cilacap dan sekitarnya dapat menjamin kelestarian sumber daya, pemanfaatannya dalam jangka panjang dan meningkatkan kesejahteraan nelayan, di samping itu dapat mengintegrasikan aspek ekologi, ekonomi, dan sosial sebagai dimensi dari perikanan yang berkelanjutan.

\section{Saran}

Agar pola pemanfaatan sumber daya udang dogol secara berkelanjutan dapat terlaksana dengan baik, maka harus dilakukan kordinasi antara pemerintah kabupaten, dan di samping itu perlu disertai dengan penegakan hukum yang tegas.

\section{DAFTAR PUSTAKA}

Dahuri, R. 2002. Regenerasi dan peningkatan kesejahteraan nelayan. Harian Kompas Jakarta. Edisi 21. Pebruari 2002. Hal.: 28.

Dall, W., B. J. Hill, P. C. Rothlisberg, \& D. J. Staples 1990. The biology of the Penaeidae. In Balxter, J. H. S \& A. J. Southward (eds): Marine biology. Vol.27. Academic Press. London, San Diego, New York, Boston, Sydney, Tokyo, Toronto. 489 p.

Gayanilo, F. C. Jr, P. Sparre, \& D. Pauly. 1993. The FISAT user's guide. FAO computerized information series fisheries. ICLARM-DIFMAR.

Gulland, J. A. 1972. Some introductory guidelines to management of shrimp fisheries, FAC, IOFC/DEV/72/74. $12 \mathrm{p}$.

Gulland, J. A. 1983. Fish stock assessment. A manual of basic methods. John Wiley \& Sons. Chicester. $233 p$.

Gunadi, W. 1981. Studi pendahuluan tentang penangkapan udang dengan trammel net di perairan Cilacap. Karya IImiah pada Fakultas Perikanan. Institut Pertanian Bogor. Bogor. 68 hal.

Haluan, J. \& T. W. Nurani. 1988. Penerapan metode scoring dalam pemilihan teknologi penangkapan ikan yang sesuai untuk dikembangkan di suatu wilayah perairan. Buletin Jurusan PSP. Hal. 3-16.

Iskandar, B. P. S, A. Suman, M. Rijal, Rusmadji, W Susanto, \& Nurwijanto. 1994. Laporan survei sumber daya udang di perairan selatan Jawa. Balai Penelitian Perikanan Laut. Jakarta.

Karyana \& Badrudin. 1992. Tingkat pemanfaatan sumber daya ikan pelagis kecil di perairan pantai barat Kalimantan. Jurnal Penelitian Perikanan Laut. No.72: 33-41.

Mangkusubroto, K. \& C. L. Trisnadi. 1985. Analisis keputusan pendekatan sistem data manajemen usaha dan proyek. Ganeca Exact. Bandung. 271 hal.

Martosubroto, P. \& N. Naamin. 1977. Relationship between tidal forest (mangroves) and commercial shrimp production in Indonesia. Marine Research in Indonesia. No. 18: 81-86.

Martosubroto, P. 1978. Musim pemijahan dan pertumbuhan udang jerbung (Penaeus 
merguiensis de Man) dan udang dogol (Metapenaeus ensis de Haan) di perairan Tanjung Krawang. Prosiding Seminar II Perikanan Udang. Hal. 7-20

Monintja, D. R. 1987. Beberapa teknologi pilihan untuk pemanfaatan sumber daya hayati laut di Indonesia. Bulletin PSP. Vol.1 No.1: 14-26.

Monintja, D. R. 2000. Prosiding pelatihan untuk pengelolaan wilayah pesisir terpadu. Pusat Kajian Sumber Daya Pesisir dan Lautan. Institut Pertanian Bogor. Bogor. Hal.: 45-57.

Naamin, N. 1972. Perkembangan perikanan udang di perairan Cilacap dan Pangandaran. Laporan Penelitian Perikanan Laut. No. 1: 59-79.

Naamin, N. 1978. Perkembangan perikanan udang di Indonesia. Prosiding Seminar II Perikanan Udang. Hal. : 55-65.

Naamin. N. 1984. Dinamika populasi udang jerbung (Penaeus merguiensis de Man) di perairan Arafura dan alternatif pengelolaannya. Disertasi Doktor pada Fakultas Pasca Sarjana. Institut Pertanian Bogor. Bogor: 381 hal.

Naamin, N., B. Sumiono, S. llyas, D. Nugroho, B. Iskandar P. S., H. R. Barus, M. Badrudin, A. Suman, dan E. M. Amin. 1992. Pedoman teknis pemanfaatan dan pengelolaan sumber daya udang penaeid bagi pembangunan perikanan. Seri: Pengembangan Penelitian Perikanan No.PHP/KAN/PT/22/1992. Badan Penelitian dan
Pengembangan Pertanian. 86 hal

Pauly, D. 1980. A selection of a simple methods for the assessment of tropical fish stocks. FAO Fish. Circ. FIRM/C 729. Roma. 54 p.

Soekartawi. 1995. Linear programming. Teori dan aplikasinya khusus dalam bidang pertarian. Penerbit Raja Grafindo Persada. Jakarta.

Sparre, P. \& S. C. Venema. 1992. Introduction to tropical fish stock assessment. Part I Manual. FAO Fish. Tech. Pap. No.306/1

Sudjastani, T. 1974. Dinamika populasi ikan kembung di Laut Jawa. Laporan Penelitian Perikanan Laut. No. 1: 30-64.

Suman, A. 1990. Beberapa aspek biologi udang dogol (Metapenaeus ensis de Haan) di perairan Pantai Selatan Jawa. Jurnal Lingkungan dan Pembangunan. 128-134.

Suman, A. 2004. Status pemanfaatan sumber daya udang dogol di perairan Cilacap dan sekitarnya. Balai Riset Perikanan Laut. Jakarta. 13 hal.

Udupa, K. S. 1986. Statistical method of estimating the size at first maturity in fishes. Fishbyte $4(2): 8$ 10. ICLARM. Metro Manila

Van Zalinge, N. P. \& N. Naamin. 1975. The Cilacap based trawl fishery for shrimp along the south coast of Java. Laporan Penelitian Perikanan Laut. No. 2: 1-15. 